\title{
Create a fine blend: An examination of institutional transition to blended learning
}

\author{
Kemran Mestan \\ La Trobe University
}

\begin{abstract}
Higher education institutions across the globe are increasing the extent to which they teach in a blended mode. However, in the rush to transition to blended teaching, institutions often fail to systematically review their transition process. Via a case study of one institution's transition to blended teaching, this paper aims to assist other institutions make similar transitions. Numerous recommendations for how institutions can advance their transition to blended learning are deduced. The investigation triangulates three data sets collected from: (1) methodical observation of the learning management system (LMS); (2) interviews with unit coordinators; and (3) a large-scale student survey. It was found that although both students and academics were receptive to blended learning, neither had a clear understanding of what it was. There is wide variability in the structure and quality of blended units and LMS sites. Lifting the standard of poorer quality blended units requires considerable investment to provide academics with time and resources. Students were on average satisfied with the online aspect of blended learning; they were particularly satisfied with procedural efficiencies, but less so with socially interactive aspects of learning. Overall, blended learning appears to enhance engagement, providing more avenues for students to engage with learning materials.
\end{abstract}

\section{Introduction}

Higher education institutions across the globe are increasing the extent to which they teach in a blended mode. The definition of blended learning will be discussed through this paper's presentation of the awareness academics have about blended learning, most simply though, blended learning is the integration of digital technology with in-person teaching practices. In the rush to transition to blended teaching, institutions often fail to systematically review their transition processes, or as Holt and colleagues (2013) note, even evaluate the implementation and effects of blended learning. The observation of Graham, Woodfield, and Harrison (2013) that research focussing on institutional policy and adoption is very limited research, focused on institutional policy and adoption issues, remains pertinent. Via a case study of one institution's transition to blended teaching, this paper aims to assist other institutions make similar transitions. Recommendations as to how institutions can advance their transition to blended learning are derived throughout the article, and these are collated in the conclusion. The investigation triangulates three data sets that were collected from: (1) methodical observation of the learning management system (LMS); (2) interviews with unit coordinators; and (3) a large-scale student survey.

After describing the context and methods of the study, the results will be presented. It was found that although both students and academics were receptive to blended learning, it appears that neither had a clear understanding of what blended learning was. There is wide variability in the structure and quality of blended units and LMS sites. Some blended units have a radically different structure to conventional inperson units, whereas other blended units use digital technology to augment conventional structures. This paper will demonstrate that lifting the standard of poorer quality blended units requires considerable investment to provide academics with time and resources.

The results section focuses on the student experience. Student opinions about blended learning remain under-researched. This might be because administrators and academics have strong views on the best ways to teach students, often reflecting their own interests rather than student experiences. For example, administrators might be motivated by financial concerns, whilst many academics are accustomed to teaching in traditional methods. Students mostly engaged in online learning on their laptops and at home. Students were on average satisfied with the online aspect of blended learning; they were particularly satisfied with procedural efficiencies, but less so with socially interactive aspects of learning. Overall, blended learning appeared to enhance engagement, providing more avenues for students to engage with learning materials. 


\section{Context and theoretical framework}

In assisting the transferability of results of this study, the institutional context of the blended learning case study is described. The institution has approximately 35,000 students, including under-graduates, postgraduates, and international students. About $18 \%$ of domestic students are from the bottom socioeconomic quartile, which is a higher proportion than the national average. The university's main campus is located in a large city, and other campuses are in rural areas. It is one of the bigger providers of rural higher education in Australia. Being a large university, it teaches across all disciplines including: science, humanities, health, business, law, engineering, education, and the arts.

The university established a target to have $60 \%$ of all units in blended mode by 2017 . To assist with achieving this target an internal research unit conducted a review of the state of blended learning at the university and the process of transitioning toward blended mode. This article is informed from this review. Ethics approval was granted from the Education Faculty Human Ethics Committee.

Taxonomies have been developed to understand various kinds of blended approaches. These taxonomies will be presented and categorised, thereby providing a meta-taxonomy to serve as a framework to position and analyse the object of this study. Graham (2012) distinguishes between enhancing, enabling, and transformative models. Enhancing blends augment conventional instruction with digital technology, such as online lectures. Enabling blends mostly aim to improve people's access to education, by means such as substituting audio visual clips for lectures, largely benefitting people who have difficulty attending classes. Lastly, transformative blends redesign units to radically alter the way students learn. Similarly, Twigg (2003) developed a supplemental, replacement, and emporium models. The supplemental model adds on activities that involve technology to conventionally structured instruction, obviously with the intention to enhance teaching. The replacement model substitutes existing in person activities with digital activities, such as web chats instead of tutorials. This has similarities with enabling blends, as the substituted technology can give people access to learning. Finally, Twigg's (2003, p. 34) emporium model refers to a kind of transformative structure, where:

[S]tudents ... choose when to access course materials, what types of learning materials to use ... and how quickly to work through the materials with the support of sophisticated instructional software and one-on-one on-site help.

This emporium model is obviously transformative. Hence, whereas Twigg (2003) describes models based on what changes are made to conventional structures, Graham (2012) focuses on the kind of impact. Alammary, Sheard, and Carbone (2014) build on this work by distinguishing models based on the extent of impact on learning, and map this over the different stages institutions undergo in transitioning to blended learning. They call the first stage a low-impact blend, which mostly involves augmenting existing units with online components. The second stage is medium impact blends, which involves replacing components. The third stage is redesigning units for blended learning, where the content, activities, interaction, and assessment incorporate digital technology and are integrated with each other. These three taxonomies are compatible and have been categorised according to the insight they bring, as seen in Table 1.

Table 1

Meta-taxonomy of blended models

\begin{tabular}{lllll}
\hline Blended Model & Nature of change & Effect on student & Extent of change & Stage of transition \\
\hline Type A & Replace & Enable & Low & Early \\
Type B & Supplement & Enhance & Medium & Mid \\
Type C & Transform & Increase choice & High & Late \\
\hline
\end{tabular}

Whereas early in the millennium Twigg (2003, p. 1148) could write that "most campuses have simply bolted new technologies", only producing outcomes as good as conventional units, institutions have increasingly moved toward more impactful forms of blended learning. In this case study, the institution's transition toward blended teaching remains in the early to mid-stage. The transition is occurring at the unit level, and thus there are varied stages of development, but most blended units involve either replacement or supplementation and therefore have a low to medium impact. Rather than entire courses being redesigned, unit coordinators are encouraged and supported to adopt blended learning. Enthusiastic 
coordinators seek out various guidance and support in blending units. Faculties develop individual strategies to serve the university blended learning target. Some faculties have identified units that are appropriate for blended learning, largely based on large student enrolments. Coordinators of those units have been supported to adapt their units. It appears the university's policies are consistent with Konsky and colleagues (2014) observation that transitioning to blended mode is advanced by complementing topdown initiatives from central administration with bottom-up initiatives led by faculties. As a result of this devolved approach, multiple forms of blended units exist at the institution. These will be further detailed in the section: Structure and content of blended units.

\section{Methods}

The case study applied mixed methods. A sample of nine blended units were examined. With the aim of gaining a cross section of units, the largest semester 1 first-year blended unit from each of the university faculties was selected (six in total). Three second-year blended units were also selected, to enable a comparison of first and second-year units. The number of students enrolled in these nine units was 5,477, which excluded students enrolled in multiple units under examination. Data were gathered from three sources: (1) examination of LMSs; (2) interviews with unit coordinators; and (3) a survey of students enrolled in the units.

The LMS sites of each of the nine units were systematically observed in May 2015. Features of each unit's LMS were identified and compared. The features were iteratively developed. Initially, features were adopted from the literature, such as online assessment, and then new features were added based on observation. Once a static array of features was developed all the LMSs were then re-examined to identify certain features, the specific form, and the extent of the feature.

Semi-structured interviews were conducted with unit coordinators from each of the nine units during semester 1, 2015. The process of developing blended units and the type of support needed was examined. Staff feedback about pedagogical implications and student engagement was also sought. Interviews were digitally recorded, transcribed, and thematically analysed.

Students enrolled in specific blended units were surveyed about their perceptions of blended learning, using an online instrument. The survey inquired about student experiences and opinions. Questions covered the quality of tuition, course material, academic support, personal support, and assessments. Students were also asked to provide any feedback related to their experience with blended learning and whether they had suggestions for improving blended learning. The survey was open from 1 June 2015 to 30 July 2015. From the 5,476 students invited to undertake the survey, 1,598 students responded, representing a $29 \%$ response rate. The demographic details of the survey respondents are presented in Table 2. Data from the survey were descriptively analysed with various correlations between demographic characteristics and responses explored.

Table 2

Demographic details of survey respondents

\begin{tabular}{llcc}
\hline Category & & $\begin{array}{c}\text { Number of survey } \\
\text { respondents }\end{array}$ & $\begin{array}{c}\text { Proportion of survey } \\
\text { respondents }\end{array}$ \\
\hline Gender & Female & 1186 & $74 \%$ \\
& Male & 412 & $26 \%$ \\
\hline Age & $<=21$ years & 1101 & $69 \%$ \\
& $>21$ years & 497 & $31 \%$ \\
\hline Campus & Bundoora & 1176 & $74 \%$ \\
& Bendigo & 271 & $17 \%$ \\
& Albury-Wodonga & 55 & $3 \%$ \\
& Mildura & 48 & $3 \%$ \\
& Shepparton & 46 & $3 \%$ \\
& Other & 2 & $0 \%$ \\
\hline Load & Full-time & 1376 & $86 \%$ \\
& Part-time & 222 & $14 \%$ \\
\hline Total & & 1598 & $100 \%$ \\
\hline
\end{tabular}




\section{Results}

\section{Awareness and understanding of blended learning}

Unit coordinators appeared to be operating with a working definition of blended learning. Academics were aware blended learning involved digital technology, with one saying: "some of the learning is happening in the classroom and some of the learning is happening online". However, some of the interviewees admitted that they were unsure what constituted blended learning, and they would like clarity from the university. For example, one unit coordinator said: "there's a little bit of a problem with ... the lack of definition of blended learning”. This suggests that the institution remains in the early stages of the transition to blended learning, as represented in Type A of the meta-taxonomy of blended models.

However, even in moving toward the mid-stage of a transition to blended learning, academics can remain confused about the definition, as it remains contentious (Alammary et al., 2014). Some researchers (Graham, 2005; Mayadas \& Picciano, 2007) contend that for a unit to be considered blended it is sufficient that it merely contain both in-person and online based learning, whereas other researchers (Gutierrez, 2006; McGee, 2014; Thorne, 2003) insist that blended learning requires the integration of inperson and online forms, and would label the mere combination of them a hybrid. The various ways a unit can be blended has also be detailed (Littlejohn \& Pegler, 2007). For example, blends can integrate different times, locations, technologies, media, and activities. Regardless of the specific definition of blended learning, this study confirms earlier research of McGee (2014), showing the importance for an institution transitioning to blended learning to provide a definition so that staff have a clear objective. The institution provided guidelines to academics about what constitutes blended learning, for example, academics were informed that online activities should complement in-person learning, rather than merely mirror them.

However, the lack of clarity unit coordinators had about blended learning might be partially explained by the observation that most of them did not choose to blend their unit, rather the unit was designated by the faculty to be blended, with unit coordinators directed or encouraged to blend their unit. Despite this directive approach, all but one of the unit coordinators recognised benefits of blended learning, especially in regard to highly subscribed units. A few of the interviewees wholeheartedly embraced blended learning. This approach taken by the institution of supporting enthusiastic academics to develop blended learning, whilst also devolving directives to faculties is supported by research. Ross and Gage (2005) stress the importance of commitment from senior executives if blended learning is to be developed well across an institution. However, much research (Hoffman, 2005; Oh \& Park, 2009; Taylor \& Newton, 2013) emphasises that success in increasing the quantity and quality of blended teaching can be enhanced via ensuring endorsement amongst staff lower in the hierarchy.

Students appeared less aware of blended learning than academics. A little less than half of survey respondents reported that they had been aware before enrolling that the unit they were taking was blended. However, part-time students had more awareness than full-time students (51\% compared to $45 \%)$.

Students who did have prior awareness that the unit was blended were asked about their preconceptions. The majority of these students were either positive (39\%) or ambivalent (52\%) about blended units. A greater proportion of part-time than full-time respondents saw the unit being blended as a positive aspect prior to commencing (57\% compared to 51\%). Additionally, a greater proportion of part-time than fulltime students reported that being able to engage with online learning greatly helped them manage their life commitments (46\% compared to 39\%), and that they would like online technology used a lot (27\% compared to 22\%). Similarly, older students (those aged 30 and over) were more aware that the unit was blended than younger students (51\% compared to 45\%), and they reported that the unit being blended greatly helped them manage other life commitments (45\% compared to 39\%). These findings suggest that blended learning helps part-time and older students manage other life commitments as asynchronous learning enables them to engage with learning at times convenient to them. These findings about older students challenge the digital natives thesis (Prensky, 2001), as older students seemed keener to engage with digital technologies than younger students. Furthermore, there was no age based difference in how respondents rated the usability of online aspects of the unit. As one unit coordinator observed: "age has 
very little to do with their capacity to work with computers ... I actually think it's a myth, the whole digital native stuff”.

\section{Structure and content of blended units}

The blended units were structured in different ways, that is, across the elements of a unit diverse digital technologies were applied to various extents and combinations. Table 3 presents the number of units that had various features. It can be seen that all but one of the units used online quizzes, whilst most of them provided online assignment submission, especially developed audio-visuals and links to existing audiovisual material.

Table 3

Key features of the sample of nine blended units

\begin{tabular}{lcc}
\hline Feature & Units with feature & Units without feature \\
\hline Online quizzes & 7 & 2 \\
Online assignment submission & 5 & 4 \\
Specially developed audio-visuals & 4 & 5 \\
Links to existing audio-visual material & 4 & 5 \\
In-person lectures & 3 & 6 \\
Recorded lecture only & 3 & 6 \\
Online exercises & 3 & 6 \\
Content based discussion forums & 3 & 6 \\
Online access to feedback of assessments & 3 & 6 \\
Externally provided modules & 2 & 7 \\
\hline
\end{tabular}

To address any discord between what features of units nominally exist and students' experiences of being enrolled in the unit, students were asked to consider to what extent of various elements of their blended unit was online (Table 3). It can be observed that administrative elements, such as submitting assignments and accessing grades were mostly online. Importantly, almost $80 \%$ of course content was online as well as two-thirds of assessments. Teacher facilitated learning and academic feedback was online to a lesser extent. This is consistent with other research showing that in the early stages of transitioning to blended learning, teachers tend to use the an LMS for administrative purposes, and provide information rather than use it as an instructional tool (Woods, Baker, \& Hopper, 2004). This is not necessarily problematic as when students were asked to what extent they would like to see each of the same features online, their preferences largely aligned with the extent to which features are currently online. However, both students and teachers alike may be unaware of the potential of online learning to facilitate interactive learning.

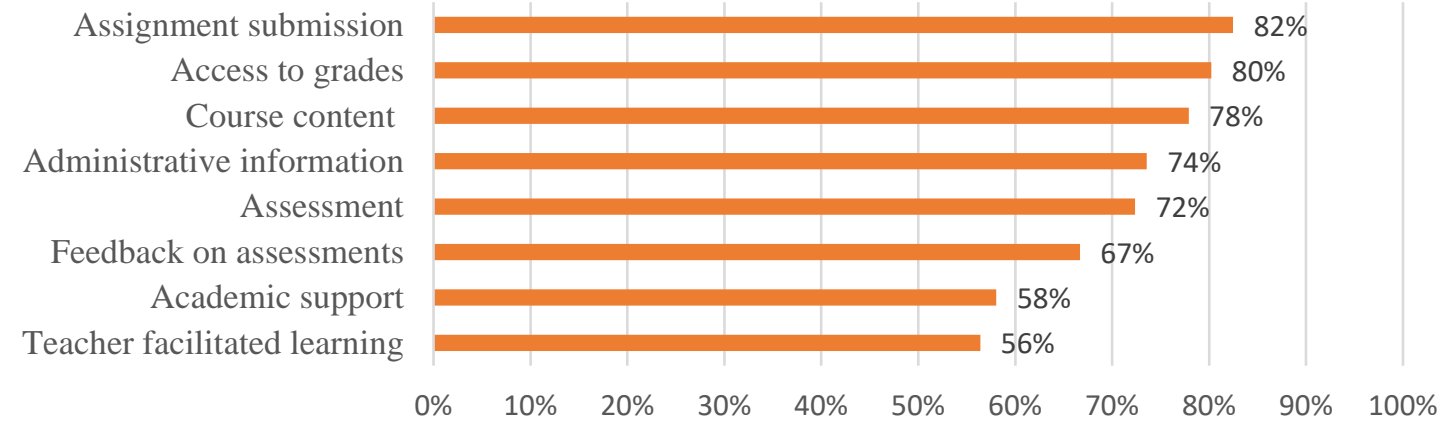

Figure 1. About what per cent of the following elements of the unit were online?

Digital technology was used in various ways across the different blended units investigated. Some unit coordinators replaced lectures with shorter recordings. In many instances lectures were divided into segments, such as five clips of 10 minutes covering the same content as a lecture. One unit coordinator pointed out that an advantage of breaking the material into smaller segments is that they can be updated 
separately. However, one unit coordinator in particular took a more radical approach. The content provided in the lectures was redesigned, whereby separate podcasts dealt with a separate learning outcomes. Unit coordinators attested that providing audio-visual clips can advance student understanding via making the content a lot clearer, with greater clarity stemming from the fact that students were able to pause, reverse, and re-watch videos.

With some blended units, recordings showed the teacher speaking at their desk, while others incorporated their voice only, overlayed on PowerPoint slides. In one instance, coordinators won a \$5000 grant from their faculty, and were able to hire video producers to help them develop recordings that integrated a range of audio-visual material. Hence, it appears that the institution is successfully transitioning to blended mode, because as Kim, Kwon, and Cho (2011) found about an under-developed blended mode, often online content remains text-based, failing to make use of the potential of digital technology. Hence, although the most advanced unit of the institution are exhibiting transformative characteristics, as with Type C models, other blended approaches remain low impact, as with Type A models.

Most students thought that the online and in-person content was integrated fairly well, with an average rating of 3.2 out of 5, with 0 meaning very poorly integrated and 5 meaning very well integrate. However, students commonly advised that content provided online should be referred to in class. If the online and class content is not integrated, then students are less likely to engage with the online content. For example, one student commented: "some aspects of the content were not discussed in class and therefore seemed pointless to learn.” It can be tempting for academics to try to cover more material by having the online and class environments focus on different content, but these findings suggest that this may not appear effective in engaging students. Rather the findings give some reason for thinking that class and online environments are better distinguished by engaging differently in the same material.

A number of students expressed a desire to have more class time to cover the online content. This is feasible in the medium term, with teaching resources being made available by shifting content online. In the short-term, teachers could create an expectation that students enrolled in the same subject register for learning communities or study groups, where they regularly meet to discuss course content (Tinto, 2012).

\section{The LMS and assessment}

There was wide variability in the appearance and functionality of LMSs, with material organised in diverse ways. For example, the homepages of some sites were mostly text based, and required students to scroll down to identify topics, whereas others had pictorial buttons. Some units provided a large range and quantity of material. It was often reported by students that they would like LMS sites to be laid out linearly, to make it clear when to engage with what material. This is consistent with other research that found well-organised online material is highly valued by students (Zuvic-Butorac, Roncevic, Nemcanin, \& Nebic, 2011). Furthermore, there was diversity in the quantity of learning materials provided through LMS sites. It was commonly suggested by students that there should be more consistency across different LMS sites, as it is difficult to adapt to the layout of each site.

Some of the units maintained separate LMS sites for different campuses, whilst others had a single LMS across campuses. When there were separate LMS sites for different campuses there were often significant differences in the sites. Conversely, a unit coordinator who applied a single LMS explained that it provided a "standardised kind of experience" for the students. In the past, lectures had been duplicated at rural campuses, but in this case the same podcast was uploaded for all students. This unit coordinator believed that blended learning provided students with more consistent information, as the LMS becomes the dominant portal of communication.

Some unit coordinators would have liked more prescription and guidance from the university in developing their LMS. However, others were reticent about standardisation, fearing it would be an additional requirement. One unit coordinator noted that some of their colleagues were protective of their LMSs and were reluctant to open them to scrutiny. To enable academics to learn from each other, it was suggested that a community of practice be established. This would enable academics to discuss their experiences about effective design and share their knowledge. 
Systematic observation of the LMSs, along with interviewing unit coordinators and surveying students, revealed that assessments could be further adapted for digital learning. Quizzes were used in most of the units, but only two of the seven units applied quizzes as assessment tasks, as opposed to merely learning exercises. Several unit coordinators stated they had learnt from experience that students only tend to do online tasks that count towards grades. One unit coordinator attested that having weekly assessed quizzes increased student preparedness for class.

Conversely, another unit coordinator believed that quizzes and other such online assessments were not appropriate for their unit. They affirmed that they are trying to help students develop skills, not simply retain information, and that in-person teaching is better for this. One particular unit coordinator wanted “to see what we can do in terms of assessment ... that wasn't just multiple choice quizzes.” The learning and teaching support unit at the university provides an online tool kit (Hannon \& Macken, 2014), which details online assessment options, as well as hyperlinks to many other resources, but it appears that academics need to be better informed about this. The assessment options covered include: group assessment, peer review, self-assessment, front-ending, and assessment reduction. McGee's (2014) metainterpretive analysis found that online assessment was more effective when a variety of assessment activities were used. The use of varied options can enable the application of authentic assessment, that is, the demonstration of skills and not just showing knowledge.

Only two units used online assessment tasks other than quizzes. In one case, where a third-party software provider was used, weekly online tasks accounted for $15 \%$ of the grade. Many of the tasks required problem solving and simulations. Tasks were often focused on mastery of skills, and the exercises could be retaken until the student was satisfied with their learning outcomes. Thus, the online technology was a formative rather than a summative assessment, enhancing learning outcomes. The unit coordinators believe that online technology improved student engagement and learning outcomes, without detracting from class time or increasing the workload of teachers. This is an example of a supplementary approach to blended learning that enhances student learning, as found in Type B blended models.

Many students expressed a desire for smaller assessments throughout the semester rather than most of the mark being dependent on a final exam. It was explained that there is so much content provided online, it can be difficult to know what to focus on for the exam. Thus, whilst final exams may have suited conventional modes of pedagogy, they may not be the most effective assessment option for blended units.

\section{Support and teacher workload}

There are two aspects of support in regard to blending units: design support and technical support. Design support relates to the structure of blended units, the appearance and functionality of the LMS, what is to be put online, what digital platforms are to be used, and how online and in-person aspects can be integrated. Most of the unit coordinators wanted to work closely with people who provided design support. One unit coordinator explained that she wanted concrete advice about redesigning curriculum and how best to apply online content, activities and assessment. This occurred, with one unit coordinator explaining that a digital support staff member helped them structure their unit, select the content of podcasts, and edit the material. Academics should not be left to themselves, design support needs to be proactive in supporting academics develop blended units, rather than reacting to requests.

Technical support mostly encompasses using software, including modifying the LMS, uploading content, sourcing quality material, integrating digital platforms into the LMS, recording material, and editing recordings. Consistent with the research of Porter and Graham (2015), unit coordinators who were innovators and early adopters, were less concerned about technical support and more interested in accessing the necessary infrastructure, such as recording booths. However, a high proportion of unit coordinators conveyed a lack of technical knowledge and emphasised the need for technical support in developing blended units. Without sufficient technical support, unit coordinators tended to be risk averse. For instance, one unit coordinator said:

I'm not willing to push the boundaries and take risks until I absolutely know that the support is there, because in big subjects, if one small thing goes wrong, that creates an absolute torrent of emails and student dissatisfaction. 
Unit coordinators commented on the increased level of support that the university is providing. This suggests that the university is transitioning from what Porter and Graham (2015) call Stage One of blended learning adoption, which is driven by merely making the strategic decision and encouraging the development of blended learning, toward Stage Two, where the necessary support and resources are provided.

There are considerable implications for academics related to the technical issues students encounter in engaging with online learning. It was observed by one unit coordinator that students often do not have necessary IT skills, such as turning on pop-ups or changing firewall settings. This accords with Taylor and Newton's (2013) finding that in applying digital tools in education, the technological knowhow of students is often overestimated. Another unit coordinator highlighted a specific technical challenge for students is that they "have very different technology systems at home ... and if it doesn't work ... it's immediately the lecturer's fault”. In the text response sections of the survey, students often complained that recordings were difficult to download or would not work on their device. Academics received many student emails requesting help or complaining. Unit coordinators reported that even if IT advice was clearly explained on the LMS, and questions were answered in forums, they continued to receive many emails seeking support. Providing this support is time consuming for academics who often teach several hundred students. One unit coordinator said about responding to emails: "it's a full-time job". This supports other research which found that a deterrent for academics in teaching blended units was the change in their roles, where they spend less time teaching content, and more time responding to technical and administrative issues (Ocak, 2011).

Most students reported that the systems had either worked very smoothly or had only a small number of glitches. However, when students do need technical help, many contact their teachers prior to the IT service desk. This highlights that the solution to prevent academics being inundated with support requests is not to improve the digital systems, as they appear to function well, but rather, to improve knowledge of the appropriate support that appears to be inevitably necessary. It is crucial that support services, including IT support, are well integrated into blended units; that is, it is apparent to students how and where to seek support whilst engaging in the unit.

Unit coordinators attested that maintaining and updating blended units requires more work than conventional units. In addition to responding to student emails, one reason for the additional work was that unit coordinators were "using lots of different ways to teach," such as engaging in online forums, monitoring online student engagement, and continually uploading new material. One unit coordinator affirmed that "maintaining the LMS is a constant project".

Besides the additional time required to manage a blended unit, there was a consensus amongst unit coordinators that the process of developing blended units increased their workload, confirming other research (Gedik, Kiraz, \& Ozden, 2013; Oh \& Park, 2009; Vaughan, 2007). Investing hours in blending a unit might not save time later either, as often academics do not re-teach the same unit many times. Unit coordinators expressed varying levels of time commitment, depending on the nature and extent of blending that occurred. For example, it was less time intensive for those who integrated externally produced modules, as well as for those who did not redesign their units. For a number of the unit coordinators, blending units was a "huge amount of work." Some unit coordinators quantified the additional work, with one explaining that: "for each week it probably took me at least 12 to 14 hours to design it, deliver it, upload it and get the LMS site going, so it was really time consuming”. Another commented that it increased their workload " 4 fold" and that "at the start it took 7 hours to develop 10 minute videos. But now it gets quicker, but still half a day at least." Lack of time was the major impediment for unit coordinators in developing blended units, hence, the main support that institutions transitioning to blended mode need to provide staff is time provision. As other research found (Alammary et al., 2014; Konsky et al., 2014), providing workload relief will facilitate institutional transition to blended mode.

\section{Student access}

Students predominantly engaged with online learning from home and via laptops (Figures 2 and 3). The second most common place students engaged in online learning was the university library. 


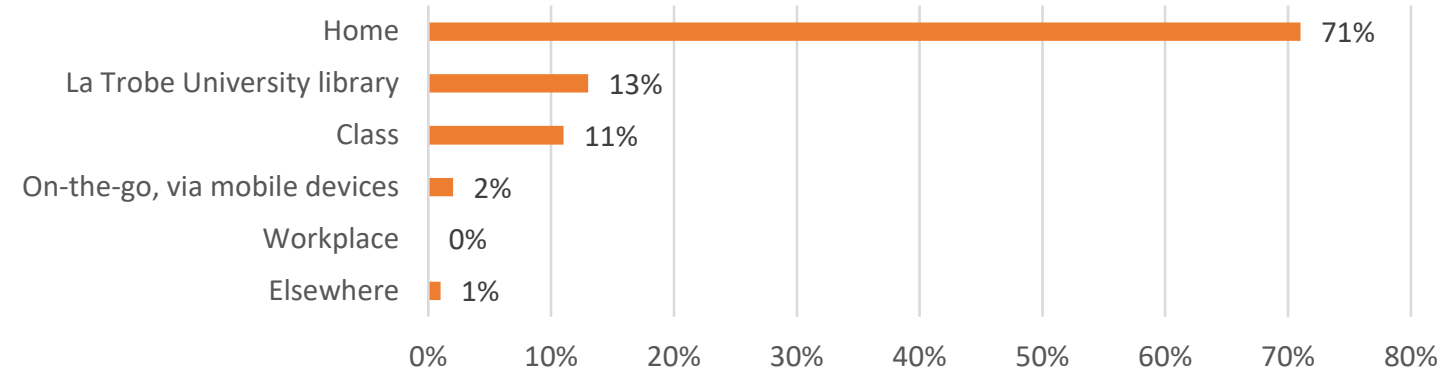

Figure 2. Responses to survey question: "In this unit, where did you mostly engage with online learning?”

One issue related to access is whether students had the necessary technology to engage with online learning; an absence of technology or outdated technology. For example, one student advised the use of a "different streaming platform for podcasts, to accommodate people with slower internet speed." Students from low socioeconomic backgrounds might be particularly vulnerable to limited technological access, which is exemplified in the following remark by a survey respondent: "It's a big expectation to think that students automatically always have access to computers or Internet". Hence, when deciding which software to integrate into digital platforms staff need to be cognisant of compatibility issues.

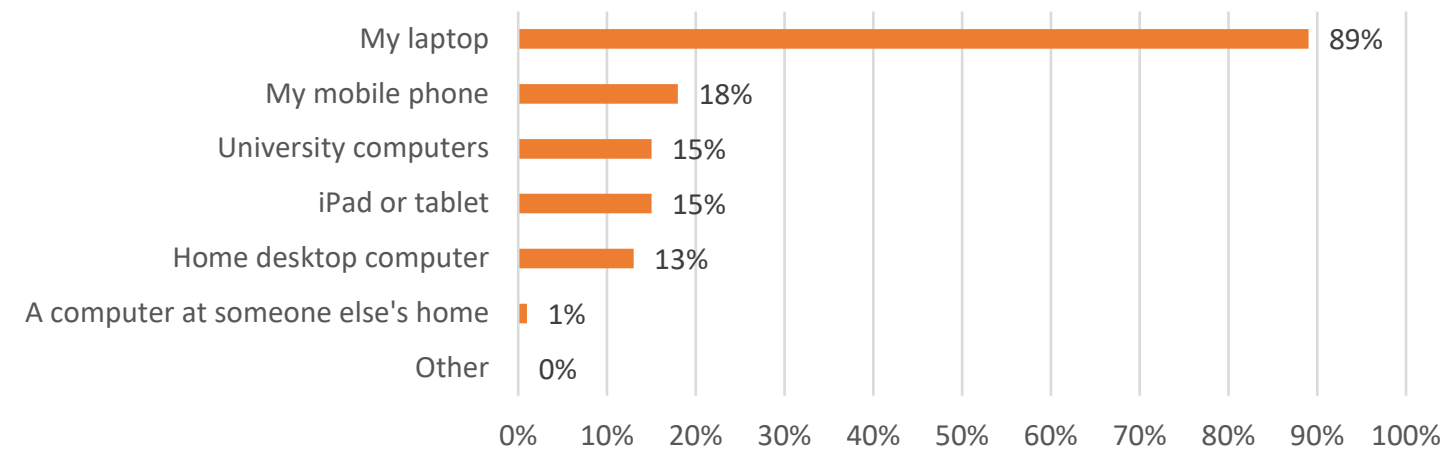

Figure 3. Responses to survey question: "What kind of computer or device do you use to access your online learning?”

It was revealing that students at rural campuses engaged in online learning in class $21 \%$ of the time compared to just $8 \%$ at the metropolitan campus. Accordingly, rural students engaged in online learning less at home (65\% compared to $74 \%$ ), and used university computers more than metropolitan students (17\% compared to 14\%). Consistent with these findings, rural students rated the adequacy of their internet access to engage in online learning lower than metropolitan students (Figure 4). This highlighted the importance of providing digital infrastructure on campuses, particularly at rural campuses. 


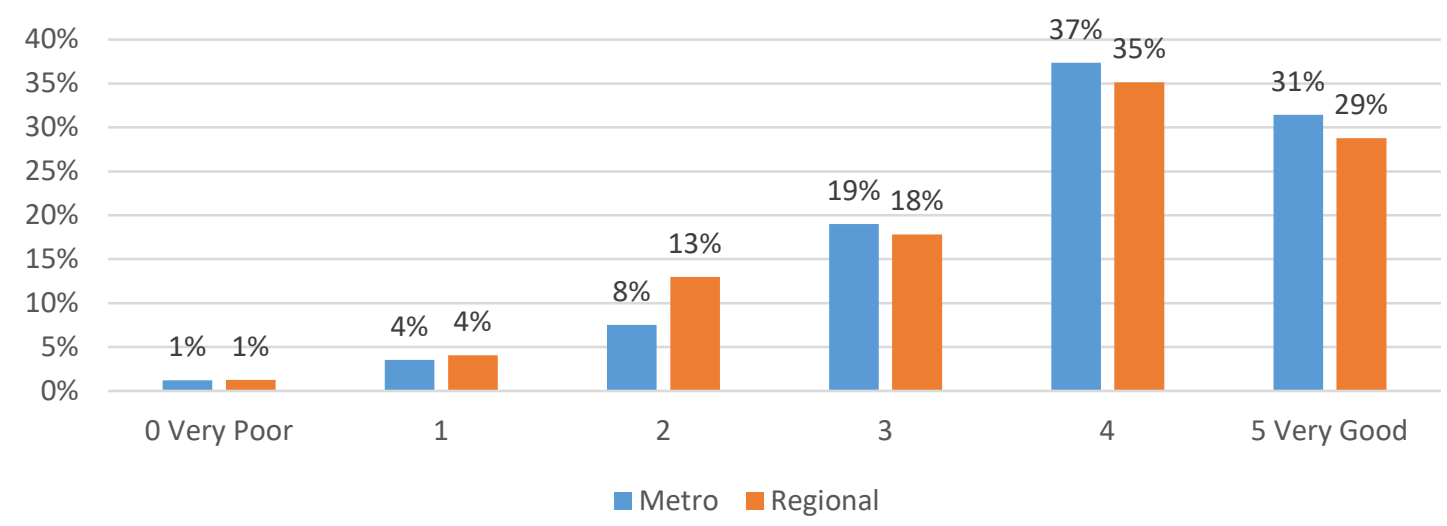

Figure 4. Responses to survey question: "Please rate the adequacy of your internet access to engage in online learning.”

\section{Student satisfaction}

Students were on average satisfied with their overall experience of blended learning, with the mean out of 5 for the relevant question being 3.2. Most of the responses clustered around this mean with a standard deviation of 1.3. A sizable proportion of respondents reported that they would like to see online technology used a lot, with only half as many preferring that it was used not much at all, but most respondents wanted online technology used somewhat (Figure 5). Some studies (Bonk, 2005; Laine, 2003) suggest that students' often struggle to adapt to blended learning, whilst other studies indicate student satisfaction with learning via online technology (So \& Brush, 2008; Zuvic-Butorac et al., 2011), thus it largely depends on the nature of the blend, as well as the demographics of students. For example, rural students were less satisfied than metropolitan students, with $17 \%$ of rural students reporting that they would not like online technology used much at all, which compares to only $9 \%$ of metropolitan students. This is likely related to the finding in the previous section that rural students have less access to digital technology.

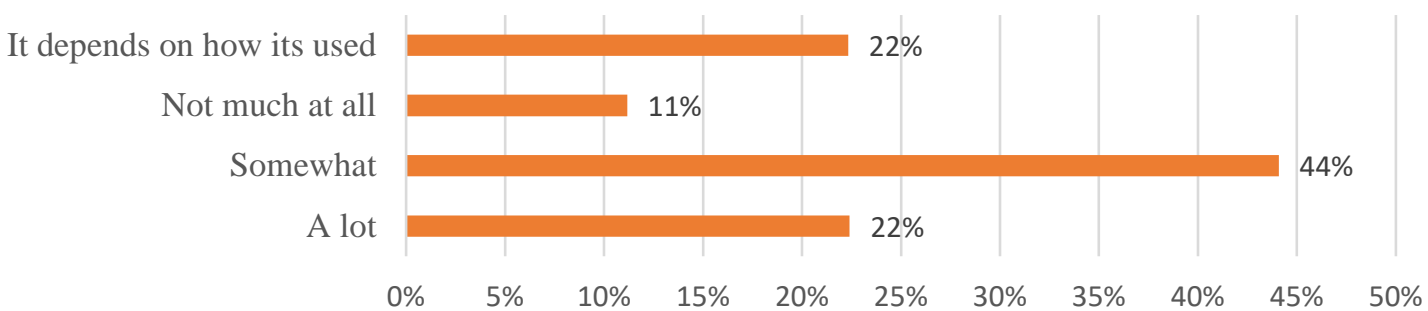

Figure 5. Responses to survey question: "In regard to units overall, to what extent would you like online technology to be used?”

In addition to overall satisfaction, students were asked about their satisfaction with specific aspects of online learning. On average, students were more satisfied with the procedural efficiencies, such as assignment submission and access to grades, than they were with academic support and feedback (Figure 6). Students also frequently commented that a major advantage of blended learning was the flexibility it provided, enabling students to engage with material when and where it was most convenient for them. This asynchronous engagement is increasingly useful to students as they work part-time at much higher rates than previously (Hall, 2010). Some students specifically mentioned that they liked that blended learning reduced the frequency that they had to come to campus, as they lived a considerable distance away. It appears that students are satisfied with elements of learning being online when those elements do not require much social interaction. The findings suggest that institutions have to focus more on improving the student experience of the interactive aspects of online learning. 


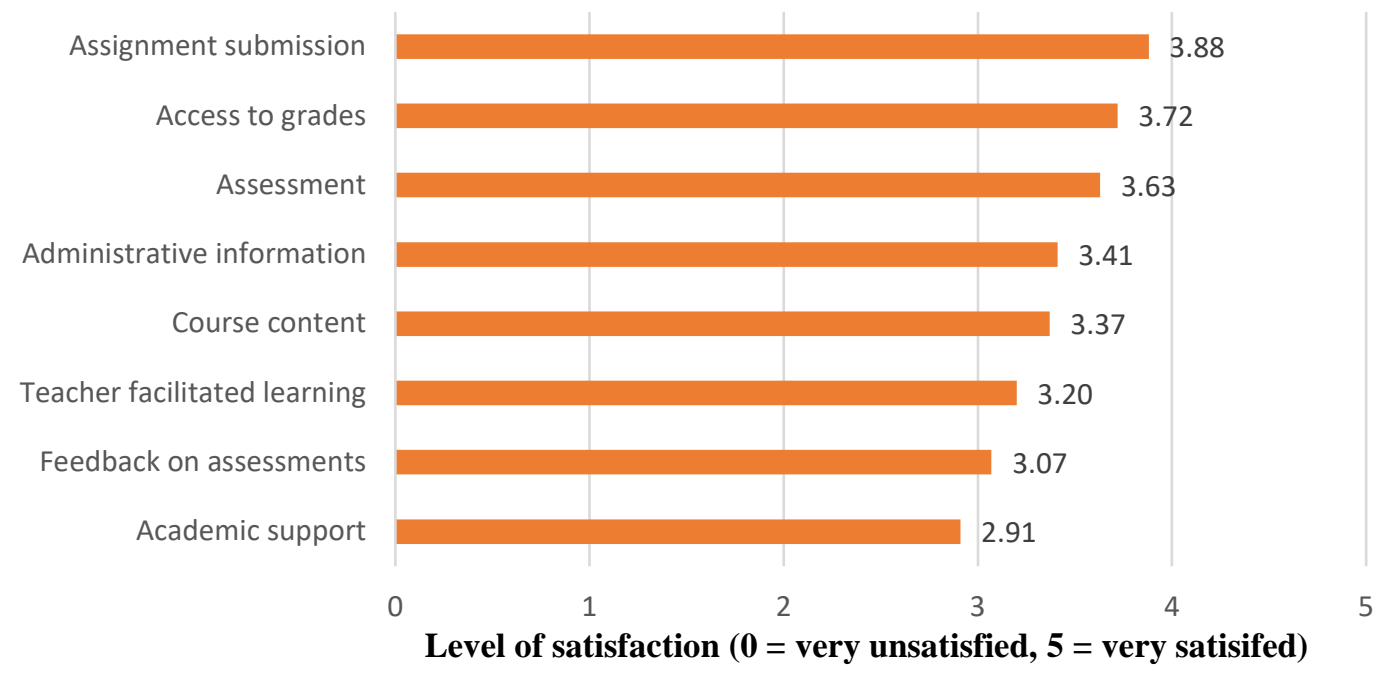

Figure 6. Responses to survey question: "How satisfied were you with online learning as applied to the following elements of the unit?”

\section{Student engagement}

Overall, unit coordinators reported that blending units enhanced student engagement, although there was some outlying feedback. Numerous unit coordinators stated that attendance in classes was often higher than it had been prior to blending their unit. For example, one unit coordinator disclosed that:

The very big thing that we've noticed is tute attendance is very high, so in the past we've probably held our tute attendance at around about $65 \%$... now it's up around $85-90 \%$ of students attending every week.

Many of the unit coordinators explained: "students are reluctant to miss class as it is the only in-person contact they have for the unit.”

Along with increased attendance, there is evidence that students are more prepared for class. For example, one unit coordinator said: "the level of preparedness is much better than in the past." Digital technology can be particularly useful for non-native speakers, as students can slow the pace of audio recordings, replay them, and often a transcription was provided, which enables students to use electronic translators when they come across unfamiliar words. A unit coordinator reported that students told them that they appreciate transcriptions being provided for this reason. The survey revealed that $48 \%$ of international students reported that the use of online learning assisted their learning a lot, compared to only $31 \%$ of domestic students. Furthermore, 28\% of international students said that they would like digital technology used $a$ lot in higher education, compared to only $22 \%$ of domestic students. This supports other research highlighting the potential of digital technology to assist non-native speakers in higher education (Choi, 2005; Koch et al., 2011).

Students may be more attracted to classes after they became blended. A unit coordinator conjectured that as a result of blending their unit, "the word's gone out to students that ... this subject is worth taking", and consequently they have "200 more students". In explaining the attraction of blended units, a couple of unit coordinators stated that prior to their units being blended, lectures were already being recorded and made available online, which lead to lecture attendance "plummeting". It was felt that blending units had added value, via higher quality audio-visual material rather than mere recorded lectures. This is the result of moving from the early stages of blended learning, where technology merely replaces practices, to supplementing teaching, as found in Type B models.

Not all students are more engaged by the integration of digital technologies. One unit coordinator observed that: "the majority of students ... really like it, but there are a minority of students that feel short changed by it, they think that they're not getting the ... face to face time”. A number of unit coordinators 
perceived that some students were cynical about the motivations of the university, believing blended learning was aimed to cut costs. This was confirmed by some student comments, for example, one student wrote: “I'm spending so much money on each unit of every semester, online learning just doesn't make me feel like that money is getting me much in return.” However, only a small minority of students made such remarks.

Unit coordinators reported that some students did not respond well to certain aspects of blended learning. For example, one unit coordinator noted that there is a need to concentrate on "not making it too different from what they're used to". The pedagogy of school is based in a class room setting with extensive contact hours. The conventional pedagogy of higher education is already a big change for many students, and blended learning usually means even less personal contact. For this reason, one unit coordinator reported that it was advisable not to assess students in the first month of a blended unit, as it takes time for students to adjust to the pedagogy. This highlights the benefits of adopting a scaffolded approach to blended learning, where teachers are more directive earlier in a unit, gradually providing more choice for students.

Unit coordinators reported that it was difficult to engage students in some online activities. Getting students to do group work via the internet was "a bridge too far”. Group wiki sites did not garner participation and students rarely engage in lively online discussion. A unit coordinator observed about their unit's online student forum that: “it's not like they're using it as a platform to have interesting discussions about the subject material, rather those who do post, usually ask specific administrative questions". This behaviour is confirmed from observation of the LMS sites. From open text comments by students in the survey, it was clear that many recognised the potential of online forums to have discussions with other students, but in practice, only a minority of students extensively contributed to forums.

More than half of the respondents to the survey reported that learning online had little effect on their connections with other students. If anything, learning online appeared to hinder connections between students. Numerous students commented that they connected with students less because they are were campus less, and spent less time in the presence of other students, which made it harder to form social bonds. This is consistent with the research of So and Brush (2008), which also found that despite not being able to develop social presence online, overall student satisfaction was not reduced. When students were asked how satisfied they were with the quality of social interaction mediated via online technology, the level of satisfaction was slightly positive (Figure 7).

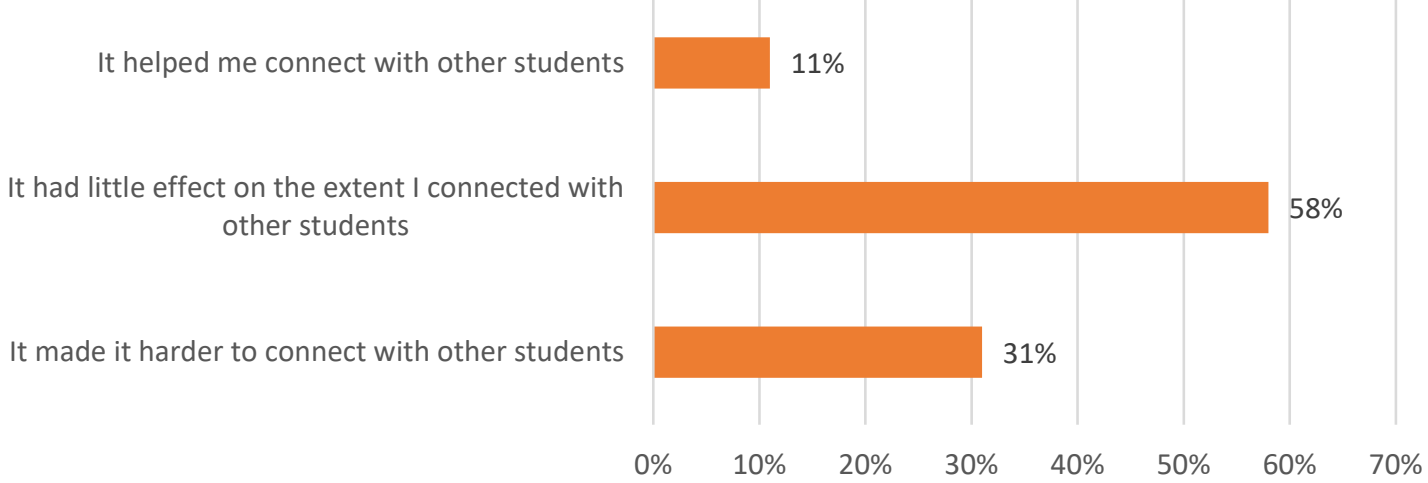

Figure 7. Responses to survey question: "Did learning online affect the extent you connected with other students?"

It appears that for students to engage in content-based online discussion and other digital technology, they need more encouragement from teachers, and potentially for it to be embedded within assessment. There are actions that teachers can take to encourage engagement with digital platforms. Specifically, one interviewee affirmed that it is important that students feel as though staff are concerned about their engagement and learning. As other research has found (Zuvic-Butorac et al., 2011) students need to feel that their online activities matter. This means that teachers should monitor and provide feedback on online participation. 
Despite the unease of some students with blended learning, two-thirds of survey respondents reported that the use of online learning assisted their learning to some degree (see Figure 8). However, rural students were less positive than metropolitan students, with almost a third reporting that online learning impeded their learning, compared to just $17 \%$ of metropolitan students. It is often assumed that online learning is more attractive to rural students as it could help them manage long distances. However, in interpreting this data, in conjunction with the earlier findings relating to where rural students access online learning and how much online learning they would like, it appears this research confirms early research that issues relating to connectivity can diminish the benefits of online learning (Block, 2010). Thus, institutions aiming to facilitate access to higher education need to be aware of a persisting digital divide.

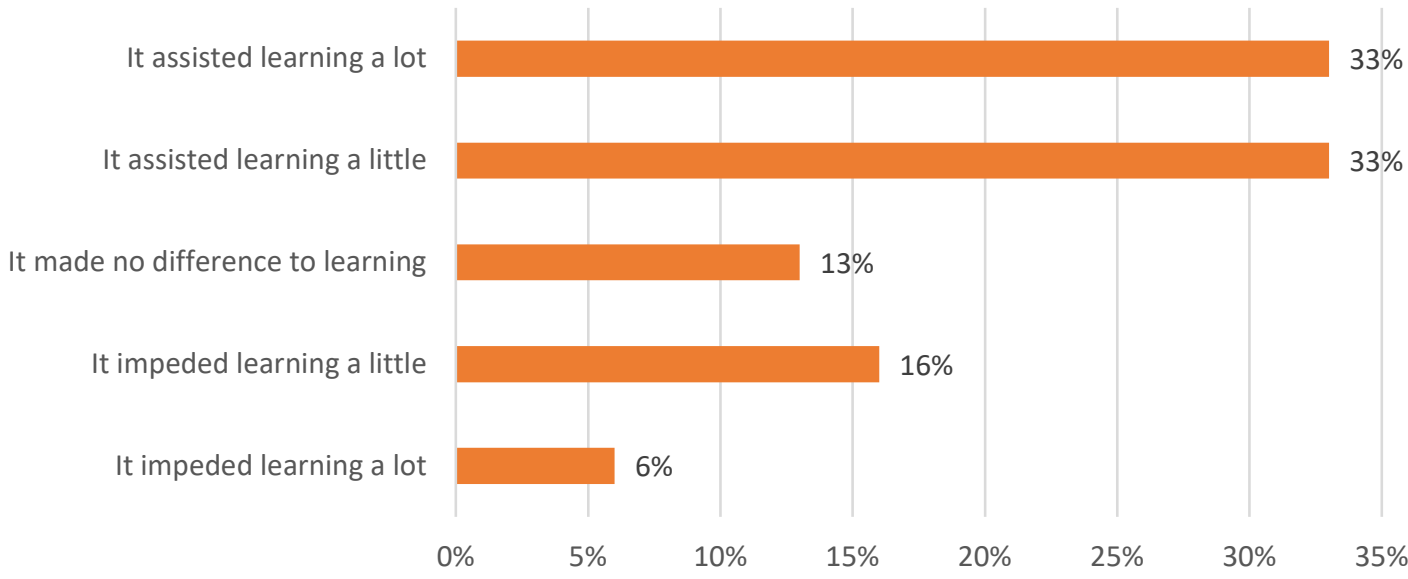

Figure 8. Responses to the survey question: "Overall, did the use of online learning assist or impede your learning?”

\section{Conclusion}

Many institutions are undergoing a similar transition toward blended learning and although individual units and courses might be evaluated, the complex process of transforming the mode of teaching and learning across an entire institution is often not systematically reviewed. The learnings from this investigation can assist other institutions in transitioning toward blended learning. Although both students and academics were receptive to blended learning, it appears that neither of them had a clear understanding of what blended learning is. Unit coordinators appeared to operate with a working definition of blended learning, with variation between unit coordinators, whilst students were mostly not aware that their units are blended. Institutions generally need to educate academics and students about the institution's own definition of blended learning, as well as the objectives and potential benefits of blended learning.

Some blended units in this case study had a radically different structure to conventional in-person units, whereas other blended units used digital technology to augment conventional structures. There was wide variability in the structure and quality of blended units, and the LMS sites specifically. Online components of blended units mostly concentrated on provision of content, with less innovation with exercises and assessment. When formative assessments were applied, this seemed to enhance student learning. Nonetheless, the potential application of digital technology to reform pedagogy remained underdeveloped, indicating that the institution has not yet moved to later stages of blended learning that transform learning to create high impacts, as with Type C models. Transitioning to more advanced blended modes requires seeking out academics whose units could be improved to advise them on integrating digital technologies into their unit, such as relating to the various online exercises and authentic assessment options. Less well organised LMS sites need to be identified and brought up to the standards of best practice at the university.

Improving the quality of blended units can only be achieved if academics are provided with sufficient design and technical support. Even more important is providing academics with additional time to 
develop blended units, as developing blended units is more labour intensive than conventional units. Blended learning is not an avenue that institutions should pursue to cut costs, as it requires considerable investment to implement well.

Students mostly engaged in online learning on their laptops and at home, but this was less the case with rural students, who used university computers to a greater extent. Hence, blended learning is unlikely to enhance the representation in higher education of rural students because a digital divide based on access to technology remains. Students were on average satisfied with the online aspect of blended learning; they were particularly satisfied with procedural efficiencies, but less so with socially interactive aspects of learning. It appears that more encouragement, monitoring, embedded assessment, and feedback is required for students to increase the extent that students engage with interactive online activities.

It was frequently remarked by students that they liked the flexibility blended learning provided, but for some students there were accessibility issues related to technological compatibility, and thus institutions need to be cognisant of using inclusive software and providing infrastructure. Blended modes of teaching can advance learning by providing more avenues for students to engage with and re-engage with learning materials. Overall, blended learning appears to enhance student engagement; it is more effective when online activities are integrated with in-person classes and assessment.

\section{Acknowledgment}

I would like to thank Dr Andrew Harvey, (Director, Centre for Higher Education Equity and Diversity Research) for supporting the production of this article.

\section{Reference}

Alammary, A., Sheard, J., \& Carbone, A. (2014). Blended learning in higher education: Three different design approaches. Australasian Journal of Educational Technology, 30(4), 440-454. https://doi.org/10.14742/ajet.693

Block, J. (2010). Distance education and the digital divide: An academic perspective. Online Journal of Distance Learning Administration, 13(1), 1-6.

Bonk, C. J. (2005). The Handbook of blended learning: Global perspectives, local designs. Hoboken, NJ: Wiley.

Choi, L. L. S. (2005). Literature review: Issues surrounding education of English-as-a-second language (ESL) nursing students. Journal of Transcultural Nursing, 16(3), 263-268. https://doi.org/10.1177/1043659605274966

Gedik, N., Kiraz, E., \& Ozden, Y. (2013). Design of a blended learning environment: Considerations and implementation issues. Australasian Journal of Educational Technology, 29(1), 1-19. https://doi.org/10.14742/ajet.6

Graham, C. R. (2005). Blended learning systems: Definition, current trends, and future directions. In C. J. Bonk, C. R. Graham, J. Cross, \& M. Moore (Eds.), Handbook of blended learning. Hoboken, NJ: Wiley. https://doi.org/10.1016/j.iheduc.2012.09.003

Graham, C. R. (2012). Blended learning systems: Definition, current trends, and future directions. In C. J. Bonk, \& C. R. Graham (Eds.), Handbook of blended learning: Global perspectives, local designs. Hoboken, NJ: Wiley.

Graham, C. R., Woodfield, W., \& Harrison, J. B. (2013). A framework for institutional adoption and implementation of blended learning in higher education. Internet and Higher Education, 18(3), 4-14. https://doi.org/10.1016/j.iheduc.2012.09.003

Gutierrez, F. M. (2006). Faculty best practices using blended learning in e-learning and face-to-face instruction. International Journal on E-Learning, 5(3), 313-337.

Hall, R. (2010). The work-study relationship: experiences of full-time university students undertaking part-time employment. Journal of Education and Work, 23(5), 439-449. https://doi.org/10.1080/13639080.2010.515969

Hannon, J., \& Macken, C. (2014). Blended and online learning curriculum design toolkit: Ideas, suggestions and worksheets for curriculum design at La Trobe. Melbourne: Learning and Teaching Unit, La Trobe University.

Hoffman, J. (2005). Why blended learning hasn't (yet) fulfilled its promise. In C. J. Bonk, C. R. Graham, J. Cross, \& M. Moore (Eds.), Handbook of blended learning. Hoboken, NJ: Wiley. 
Holt, D., Palmer, S., Munro, J., Solomonides, I., Gosper, M., Hicks, M., ... Hollenbeck, R. (2013). Leading the quality management of online learning environments in Australian higher education. Australasian Journal of Educational Technology, 29(3), 387-402. https://doi.org/10.14742/ajet.84

Kim, J., Kwon, Y., \& Cho, D. (2011). Investigating factors that influence social presence and learning outcomes in distance higher education. Computers \& Education, 57(2), 1512-1520. https://doi.org/10.1016/j.compedu.2011.02.005

Koch, J., Salamonson, Y., Du, H. Y. B., Andrew, S., Frost, S., Dunncliff, K., \& Davidson, P. (2011). Value of web-based learning activities for nursing students who speak English as a second language. Journal of Nursing Education, 50(7), 373-380. https://doi.org/10.1177/104365969901000208

Laine, L. (2003). Is e-learning effective for IT training. $T+D, 56(6)$, 55-60.

Littlejohn, A., \& Pegler, C. (2007). Preparing for blended e-learning: Understanding blended and online learning (connecting with e-learning). London: Routledge.

Mayadas, A. F., \& Picciano, A. G. (2007). Blended learning and localness: The means and the end. Journal of Asynchronous Learning Networks, 11(1), 3-7.

McGee, P. (2014). Blended course design: Where's the pedagogy? International Journal of Mobile and Blended Learning, 6(1), 33-55. https://doi.org/10.4018/ijmbl.2014010103

Ocak, M. A. (2011). Why are faculty members not teaching blended courses? Insights from faculty members. Computers \& Education, 56(3), 689-699. http://dx.doi.org/10.1016/j.compedu.2010.10.011

Oh, E., \& Park, S. (2009). How are universities involved in blended instruction? Educational Technology \& Society, 12(3), 327-342.

Porter, W. W., \& Graham, C. R. (2015). Institutional drivers and barriers to faculty adoption of blended learning in higher education. British Journal of Educational Technology, 47(4), 748-762. https://doi.org/10.1111/bjet.12269

Prensky, M. (2001) Digital natives, digital immigrants. On the Horizon, 9(5), 1-6. https://doi.org/10.1108/10748120110424816

Ross, B., \& Gage, K. (2005). Global perspectives on blending learning. In C. J. Bonk, C. R. Graham, J. Cross, \& M. Moore, J (Eds.), Handbook of blended learning. Hoboken, NJ: Wiley.

So, H.-J., \& Brush, T. A. (2008). Student perceptions of collaborative learning, social presence and satisfaction in a blended learning environment: Relationships and critical factors. Computers \& Education, 51(1), 318-336. https://doi.org/10.1016/j.compedu.2007.05.009

Taylor, J. A., \& Newton, D. (2013). Beyond blended learning: A case study of institutional change at an Australian regional university. Internet and Higher Education, 18(1), 54-60. https://doi.org/10.1016/j.iheduc.2012.10.003

Thorne, K. L. (2003). Blended learning: How to integrate online and traditional learning. London: Kogan Page.

Tinto, V. (2012). Completing college: Rethinking institutional action. Chicago, IL: University of Chigago Press. https://doi.org/10.7208/chicago/9780226804545.001.0001

Twigg, C. A. (2003). Improving learning and reducing costs: New models for online learning. EDUCAUSE Review, 38(5), 28-38.

Vaughan, N. D. (2007). Perspectives on blended learning in higher education. International Journal on ELearning, 6(1), 81-94.

Von Konsky, B. R., Martin, R., Bolt, S., Broadley, T., \& Ostashewski, N. (2014). Transforming higher education and student engagement through collaborative review to inform educational design. Australasian Journal of Educational Technology, 30(6), 619-633. https://doi.org/10.14742/ajet.742

Woods, R., Baker, J. D., \& Hopper, D. (2004). Hybrid structures: Faculty use and perception of webbased courseware as a supplement to face-to-face instruction. The Internet and Higher Education, 7(4), 281-297. http://dx.doi.org/10.1016/j.iheduc.2004.09.002

Zuvic-Butorac, M., Roncevic, N., Nemcanin, D., \& Nebic, Z. (2011). Blended e-learning in higher education: research on students' perspective.(Technical report). Issues in Informing Science \& Information Technology, 8(1), 409. https://doi.org/10.28945/1427

Corresponding author: Kemran Mestan, kemranm@gmail.com Australasian Journal of Educational Technology (C) 2019.

Please cite as: Mestan, K. (2019). Create a fine blend: An examination of institutional transition to blended learning. Australasian Journal of Educational Technology, 35(1), 70-84.

https://doi.org/10.14742/ajet.3216 